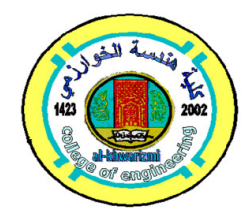

Al-Khwarizmi Engineering Journal, Vol. 16, No. 2, June, (2020)

P.P.34- 46

Al-Khwarizmi

Engineering

Journal

\title{
Prediction of Cutting Force in Turning Process by Using Artificial Neural Network
}

\author{
Marwa Qasim Ibraheem \\ Department of Production Engineering and Metallurgy/ University of Technology/ Baghdad/Iraq \\ Email: 70223@uotechnology.edu.iq
}

(Received 23 October 2019; accepted 26 April 2020)

https://doi.org/10.22153/kej.2020.04.002

\begin{abstract}
Cutting forces are important factors for determining machine serviceability and product quality. Factors such as speed feed, depth of cut and tool noise radius affect on surface roughness and cutting forces in turning operation. The artificial neural network model was used to predict cutting forces with related to inputs including cutting speed ( $\mathrm{m} / \mathrm{min}$ ), feed rate $(\mathrm{mm} / \mathrm{rev})$, depth of cut $(\mathrm{mm})$ and work piece hardness (Map). The outputs of the ANN model are the machined cutting force parameters, the neural network showed that all (outputs) of all components of the processing force cutting force FT $(\mathrm{N})$, feed force FA $(\mathrm{N})$ and radial force FR $(\mathrm{N})$ perfect accordance with the experimental data. Twenty-five samples of experimental data were used, including nineteen to train the network. Moreover six other experimental tests were implemented to test the network. The study concludes that ANN was a dependable and precise method for predicting machining parameters in CNC turning operation.
\end{abstract}

Keywords: Cutting force, ANN, turning operation.

\section{Introduction}

Turning operation is a very rife material removal technique in manufacturing field; Researches treat with several sides like: geometric and metallurgical feature of the cutting tool, work piece material effect on the operation and process parameters like (cutting speed, feed rate, and depth of cut). hard turning operation produce high cutting forces and temperatures that effect on cutting parameters, The influence of all these factors give rise to concatenation of physical, chemical and thermo-mechanical phenomena that effect on metal so modeling of cutting forces is necessary [1].

The machining force in turning process is a three-dimensional vector. Three components represent it, namely the cutting force $\mathrm{Ft}$ which is in the direction of cutting axis, the radial force $\mathrm{Fr}$ in the direction of radial axis and feed force $\mathrm{Fa}$ in the direction of feed axis the cutting force has the biggest value in the three force components. Several researchers learned such components and taking into accounts the effect of cutting variables Stachurski, et al. [2] utilized a power polynomial to model the cutting force during turning steel C45.

Astakhov and Xiao [3] applied mathematical models to estimate the cutting forces during machining two materials, aerospace aluminum alloy 2024 and T6AISI bearing steel E52100.

Hrinath Gowd et al. [4] performed experiments involving the effect of cutting forces and surface roughness, which were appreciably influenced by cutting speed, feed and depth of cut, then developed a second order polynomial model in which studied The effect of operating parameters on cutting forces and surface roughness and used RSM for the prediction of mathematical models for estimation of $\mathrm{Fx}, \mathrm{Fy}, \mathrm{Fz}$ and surface roughness. 
Bouacha et al. [5] during machining of AISI 52100 Steel with CBN tool show the effect of operating parameters speed, feed and depth of cut on cutting forces and surface roughness by Using three level factorial design, the study showed that surface roughness effected by feed rate and cutting speed, while cutting forces influenced by depth of cut.

In this work, an ANN process is suggest to predict cutting force components in hard turning feed force Fa, radial force Fr and cutting force Ft.

An artificial neural network model is a powerful method to deal with nonlinear functions or to model systems with unknown input-output relations [6-7].

In experimental procedures a lot of money is wasted as well as time. Used (ANN) as a powerful and accurate tool for machining process modeling to avoid this, where it succeeded in providing an accurate theoretical model and showed accuracy in the modeling of cutting forces quicker than numerous methods that used in complex machining operations such as milling and turning Budak et al. [8].

Szecsi et al. [9], an analytical model was used which gave the average predictive error $(9.5 \%)$ on the cutting forces and also provided a neural network for training with an average error rate (3.5\%.) where the cutting forces were modeled based feed-forward multilayered neural networks were trained by BP algorithm that inspected the effect of two main factors affecting on error convergence namely education rate $\eta$ and momentum term $\alpha$.

The neural network is trained on the cases that are reversed during the training process as it is distinguishing by being able to find a base linking outputs to inputs through training operation [10, $11]$.

Mohanned H.AL-Khafaji[12], built a neural network model in which the cutting parameters were optimize to produce the lowest machining force and the study showed compatibility with experimental data and the calculated correlation coefficients were equal to one.

This paper aims to build a neural network model to link the cutting variables, work piece hardness, cutting speed, cutting depth, feed rate, to the machining Force during machining of AISI 52100 bearing steel and providing an accurate model for modeling cutting forces faster relying on operating parameters and creating a rule that connects inputs and outputs through training operations.

\section{Experimental Work}

An empirical data set of cutting forces measured through hard turning of AISI 52100 bearing steel with CBN tool.

\subsection{Work Piece Material}

AISI 52100 steel is great used for a diversity of applications that used in bearings and rotating machinery. Like valve bodies, pumps and fittings, etc. schedule $(1,2)$ display the mechanical properties and chemical composition of AISI 52100 steel respectively.

Experiments were accomplished dry straight turning operation using lathe type SN 40 and AISI 52100 bearing steel as a work piece material with round bars (40 $\mathrm{mm}$ diameter and $250 \mathrm{~mm}$ length) with chemical composition in schedule (2) . Tool used is CBN 7020, the rake angle $\gamma=12^{\circ}$, clearance angle $\alpha=9^{\circ}$, helix angle $\lambda=25^{\circ}$, the cutting zone shown in Figure (1), Figure (2) shows components of machining force.

Table 1,

Mechanical properties AISI 52100 bearing steel.

\begin{tabular}{llllll}
\hline Tensile & Yield & Bulk modulus & Shear modulus & Poisson's ratio & Thermal conductivity \\
\hline $\mathrm{MPa}$ & $\mathrm{Mpa}$ & $\mathrm{Gpa}$ & $\mathrm{Gpa}$ & & $\mathrm{W} / \mathrm{m} . \mathrm{K}$ \\
520 & $415 \mathrm{Min}$ & 140 & 80 & $0.27-0.30$ & 46.6 \\
\hline
\end{tabular}

Table 2,

The typical Chemical composition of AISI 52100 bearing steel.

\begin{tabular}{lllllll}
\hline & Si & Mn & P & S & C & Cr \\
MIN MAX\% & $0.15 \sim 0.35$ & $0.25 \sim 0.45$ & $\leq 0.015$ & $\leq 0.015$ & $0.95 \sim 1.10$ & $1.35 \sim 1.60$ \\
\hline
\end{tabular}




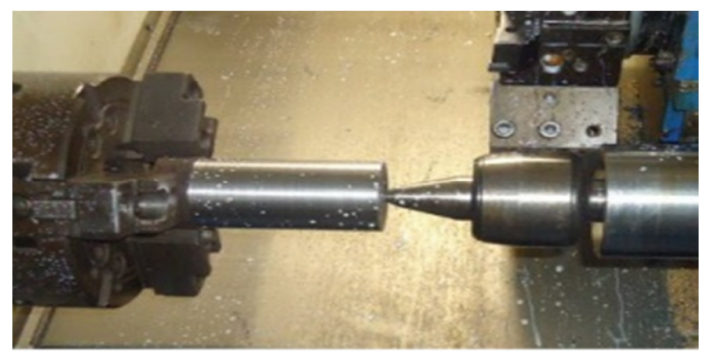

Fig. 1. Cutting zone.

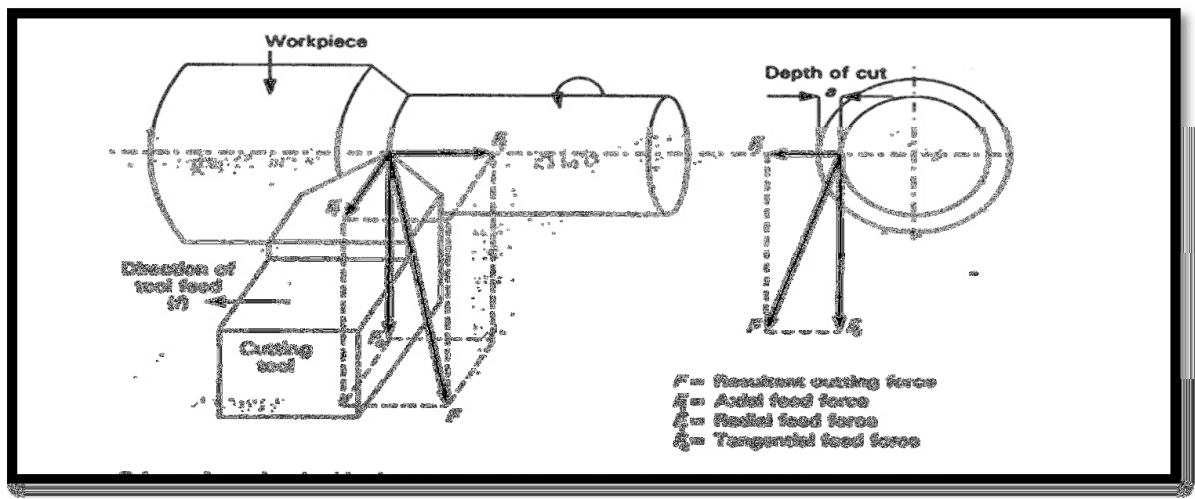

Fig. 2. Components of machining force [13].

\subsection{Artificial Neural Network}

After execution the experiments at design matrix, output response Measured and recorded be obvious in the schedule (3) cutting speed, feed, cutting depth and work piece hardness are taken as input parameter.

Table 3,

Experimental dataset.

\begin{tabular}{llllllll}
\hline & HRC & Speed & Feed & Depth of cut & FT(N) & FR(N) & FA(N) \\
\hline 1 & 45 & 100 & 0.05 & 0.15 & 55.325 & 100.3 & 15.4 \\
2 & 50 & 150 & 0.10 & 0.15 & 81.205 & 85.505 & 25.905 \\
3 & 52 & 200 & 0.15 & 0.15 & 105.297 & 83.725 & 28.153 \\
4 & 54 & 250 & 0.20 & 0.15 & 129.389 & 35.945 & 29.156 \\
5 & 56 & 300 & 0.30 & 0.15 & 164.9 & 122.2 & 32.604 \\
6 & 52 & 150 & 0.05 & 0.20 & 72.172 & 73.06 & 34.313 \\
7 & 54 & 200 & 0.10 & 0.20 & 96.264 & 94.28 & 35.316 \\
8 & 56 & 250 & 0.15 & 0.20 & 120.4 & 85.5 & 35.316 \\
9 & 45 & 300 & 0.20 & 0.20 & 136.7 & 123.59 & 36.319 \\
10 & 50 & 100 & 0.30 & 0.20 & 201.92 & 189.84 & 47.98 \\
11 & 56 & 200 & 0.05 & 0.25 & 7.231 & 81.835 & 42.479 \\
12 & 45 & 250 & 0.10 & 0.25 & 113.6 & 109.5 & 40.245 \\
13 & 50 & 300 & 0.15 & 0.25 & 145.895 & 114.175 & 39.55 \\
14 & 52 & 100 & 0.20 & 0.25 & 167.247 & 154.395 & 52.698 \\
15 & 54 & 150 & 0.30 & 0.25 & 216.979 & 198.615 & 56.146 \\
16 & 50 & 250 & 0.05 & 0.30 & 96.33 & 80.51 & 48.155 \\
17 & 52 & 300 & 0.10 & 0.30 & 120.422 & 101.73 & 49.158 \\
18 & 54 & 100 & 0.15 & 0.30 & 158.214 & 141.95 & 59.861 \\
19 & 56 & 150 & 0.20 & 0.30 & 172.3 & 103.2 & 60.864 \\
20 & 45 & 200 & 0.30 & 0.30 & 224.29 & 194.26 & 61.075 \\
21 & 54 & 300 & 0.05 & 0.40 & 126.804 & 97.82 & 65.431 \\
22 & 56 & 100 & 0.10 & 0.40 & 164.596 & 183.04 & 76.134 \\
23 & 45 & 150 & 0.15 & 0.40 & 180.94 & 146.13 & 73.9 \\
24 & 50 & 200 & 0.20 & 0.40 & 206.8 & 194.4 & 79.7 \\
25 & 52 & 250 & 0.30 & 0.40 & 256.432 & 214.6 & 79.338 \\
\hline
\end{tabular}


Neural network models are used to predict FT, FR and FA respectively Levenberg Marquardt algorithm was chosen due to its high accuracy in similar function approximation [14] that used to train the networks in order to improve the generalization of the network, a regularization ${ }^{\text {ee }}$ scheme was used in conjunction with the Levenberg-Marquardt algorithm. The input/output dataset was divided randomly into two categories: training dataset and test dataset. The automatic Bayesian Regularization was used for training with Levenberg Marquardt combined with Bayesian regularization.
Two steps were used to model ANN; First for training, whereas second for testing the network. two layer back propagation network was employed As a tool for mapping the complex and highly inter-active process parameters such as cutting speed, feed, depth of cut and work piece hardness.

The Input data, target data set and testing data used in ANN modeling are shown in Tables (4\&5) respectively

Table 4,

Input Dataset and Target data

\begin{tabular}{llllllll}
\hline \multicolumn{2}{l}{ Input Dataset } & & & \multicolumn{3}{l}{ Target data. } \\
Exp No. & HRC & Speed & Feed & Depth of cut & FT(N) & FR(N) & FA(N) \\
\hline 2 & 50 & 150 & 0.10 & 0.15 & 81.2 & 85.5 & 25.9 \\
3 & 52 & 200 & 0.15 & 0.15 & 105.3 & 89.7 & 28.2 \\
4 & 54 & 250 & 0.20 & 0.15 & 129.4 & 95.9 & 29.2 \\
6 & 52 & 150 & 0.05 & 0.20 & 72.2 & 73.1 & 34.3 \\
7 & 54 & 200 & 0.10 & 0.20 & 96.3 & 94.3 & 35.3 \\
9 & 45 & 300 & 0.20 & 0.20 & 136.7 & 123.6 & 36.3 \\
10 & 50 & 100 & 0.30 & 0.20 & 161.9 & 189.8 & 47.9 \\
11 & 56 & 200 & 0.05 & 0.25 & 87.2 & 81.8 & 42.5 \\
13 & 50 & 300 & 0.15 & 0.25 & 145.9 & 114.2 & 39.6 \\
14 & 52 & 100 & 0.20 & 0.25 & 167.2 & 154.4 & 52.7 \\
15 & 54 & 150 & 0.30 & 0.25 & 176.9 & 99.6 & 56.1 \\
16 & 50 & 250 & 0.05 & 0.30 & 96.3 & 80.5 & 48.2 \\
17 & 52 & 300 & 0.10 & 0.30 & 130.4 & 98.7 & 49.2 \\
18 & 54 & 100 & 0.15 & 0.30 & 158.2 & 141.9 & 59.9 \\
20 & 45 & 200 & 0.30 & 0.30 & 184.3 & 190.3 & 63.1 \\
21 & 54 & 300 & 0.05 & 0.40 & 126.8 & 97.8 & 65.4 \\
22 & 56 & 100 & 0.10 & 0.40 & 164.6 & 146.0 & 76.1 \\
23 & 45 & 150 & 0.15 & 0.40 & 180.9 & 184.1 & 77.9 \\
25 & 52 & 250 & 0.30 & 0.40 & 189.4 & 198.6 & 82.3 \\
\hline
\end{tabular}

Table 5,

Testing data

\begin{tabular}{lllll}
\hline Exp No & HRC & Feed & Speed & Depth of cut \\
\hline 1 & 45 & 0.05 & 100 & 0.15 \\
5 & 56 & 0.30 & 300 & 0.15 \\
8 & 56 & 0.15 & 250 & 0.20 \\
12 & 45 & 0.10 & 250 & 0.25 \\
19 & 56 & 0.20 & 150 & 0.30 \\
24 & 50 & 0.20 & 200 & 0.40 \\
\hline
\end{tabular}

\section{Results and Discussion 3.1 Analysis of Variance}

The experimental results were from table (3) analyzed with an analysis of variance (ANOVA), which they are used to determine the factors that most influence the performance characteristics (cutting forces) are shown in Table $(6,7$, and 8) respectively.

The overall significant of mathematical model can be seen in table $(6,7,8)$ respectively ,the greatest value of $\mathrm{F}$ ratio among the variables was (18.88) for feed accordingly the mostly effected variable on FR with p-value (0.000) and R$\mathrm{sq}(\operatorname{adj})=85.15 \%$ as see in schedule $(6)$. 
From schedule (7) the most influence variable is depth of cut with $\mathrm{F}$ ratio (333.46), pvalue $(0.000)$ and $R-s q(\operatorname{adj})=98.40 \%$ for $F A$. From schedule ( 8 )the most influence variable on
FT value was fee with $\mathrm{F}$ ratio (861.72), p-value $(0.000)$ and $\mathrm{R}-\mathrm{sq}(\mathrm{adj})=99.51 \%$.

Figure $(3,4,5)$, illustrate the Residual Plot for FR,FA,FT respectively .

Table 6,

Analysis of variance for FR

\begin{tabular}{llllll}
\hline Source & DF & Adj-SS & Adj-MS & F-Value & P-Value \\
\hline Speed & 4 & 7163 & 1790.8 & 5.24 & 0.023 \\
Feed & 4 & 25800 & 6449.9 & 18.88 & 0.000 \\
Depth & 4 & 17599 & 4399.7 & 12.88 & 0.001 \\
HRC & 4 & 1900 & 475.0 & 1.39 & 0.320 \\
Error & 8 & 2733 & 341.6 & & \\
Total & 24 & 55194 & & & \\
\hline \multicolumn{7}{l}{ R-sq= 95.05\% } & R-sq(adj)=85.15\% R-sq(pred)=71.65\% & \\
\hline
\end{tabular}

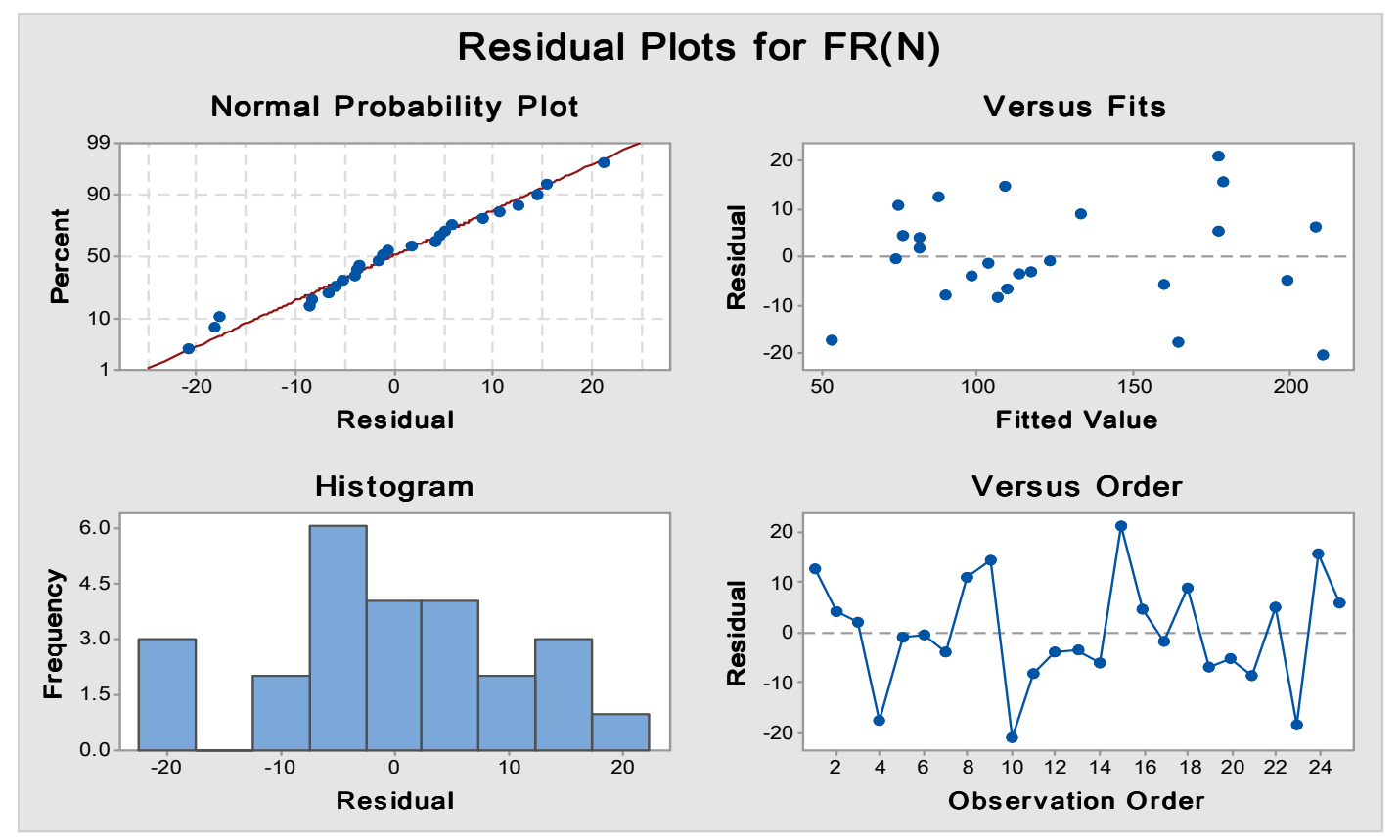

Fig. 3. Residual Plot for FR

Table 7,

Analysis of variance for $\mathrm{FA}$

\begin{tabular}{llllll}
\hline Source & DF & Adj-SS & Adj-MS & F-Value & P-Value \\
\hline Speed & 4 & 131.39 & 32.85 & 6.42 & 0.013 \\
Feed & 4 & 616.43 & 154.11 & 30.14 & 0.000 \\
Depth & 4 & 6820.81 & 1705.20 & 333.46 & 0.000 \\
HRC & 4 & 53.98 & 13.49 & 2.64 & 0.113 \\
Error & 8 & 40.91 & 5.11 & & \\
Total & 24 & 7663.52 & & & \\
\hline
\end{tabular}




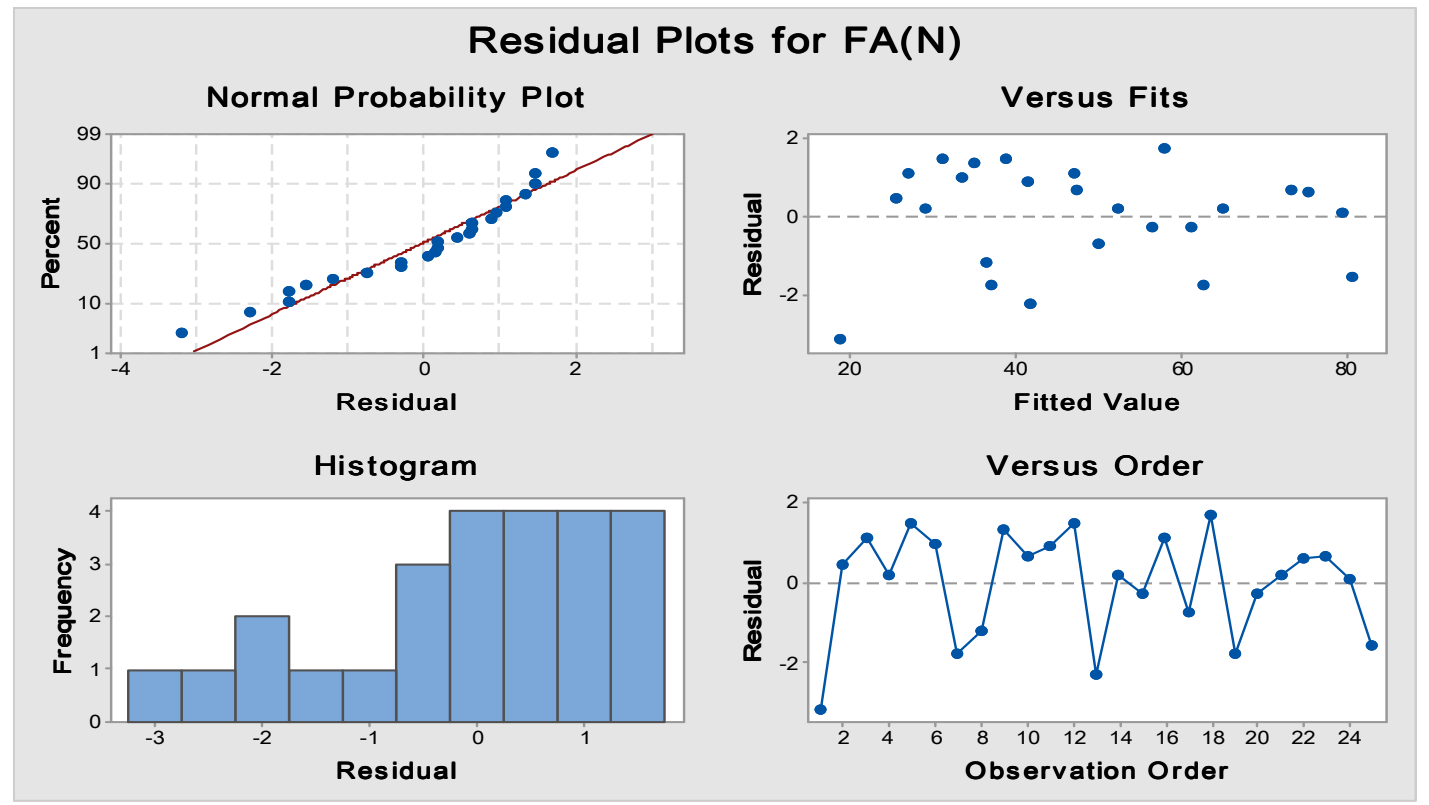

Fig. 4. Residual Plot for FA.

Table 8,

Analysis of variance for FT

\begin{tabular}{llllll}
\hline Source & DF & Adj-SS & Adj-MS & F-Value & P-Value \\
\hline Speed & 4 & 282.3 & 70.6 & 5.34 & 0.022 \\
Feed & 4 & 45527.4 & 11381.9 & 861.72 & 0.000 \\
Depth & 4 & 18325.3 & 4581.3 & 346.85 & 0.000 \\
HRC & 4 & 80.7 & 20.2 & 1.53 & 0.282 \\
Error & 8 & 105.7 & 13.2 & & \\
Total & 24 & 64321.4 & & & \\
\hline \multicolumn{7}{l}{ R-sq=99.84\% } & R-sq(adj)=99.51\% & R-sq(pred)=98.40\% & & \\
\hline
\end{tabular}

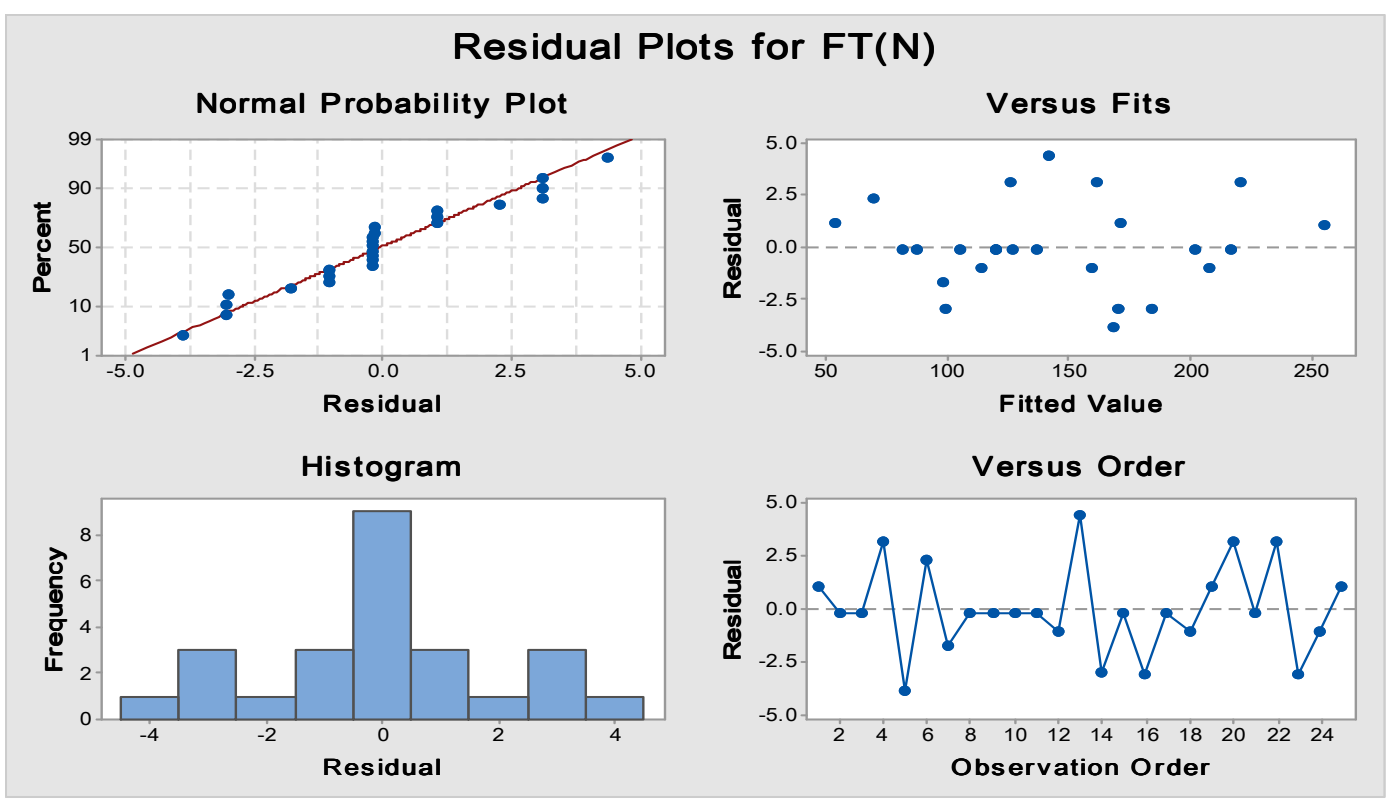

Fig. . 5. Residual Plot for FT. 
While, the mathematical model for FR,FA,FT are developed as shown in equations $(1,2,3)$ to represent the relationship between the input parameters speed(S), feed(F),depth of cut(D) ,work piece hardness (HRC) and the response FR,FA,FT

$\mathbf{F R}(\mathbf{N})=124.40+29.50 \mathrm{~S}-100$

+ 5.30 S-200- 19.19 S-250- 12.50 S-300- 37.70 F-

0.05- 9.59 F_0.10- 10.11 F-0.15-2.10 F-0.20

+ 59.50 F-0.30- 38.87 D-0.15- 11.15 D-

$0.20+7.30$ D-0.25- 0.07 D-0.30+ 42.79 D-

$0.40+10.35$ HRC-45 + 8.48 HRC-50

+ 1.10 HRC-52 - 10.68 HRC-54 - 9.25 HRC-56

$\mathbf{F A}(\mathbf{N})=48.208+2.207 \mathrm{~S}-100+2.018 \mathrm{~S}-150$

+1.137 S-200 - 1.766 S-250- 3.595 S-300-

7.052 F-0.05- 2.856 F-0.10- 0.852 F-

$0.15+3.540 \mathrm{~F}-0.20+7.221 \mathrm{~F}-0.30-21.964 \mathrm{D}-$

0.15- 10.359 D-0.20- 1.984 D-0.25+ 7.615 D-

$0.30+26.693$ D-0.40- 2.820 HRC-

45+ 0.050 HRC-50+ 0.524 HRC-52

+0.974 HRC-54 + 1.272 HRC-56
$\mathbf{F T}(\mathbf{N})=144.066+5.39 \mathrm{~S}-100+0.65 \mathrm{~S}-150$ 0.09 S-200- 0.84 S-250- 5.12 S-300- 56.49 F-

0.05- 28.85 F-0.10- 1.92 F-0.15+ 18.42 F-0.20

+68.84 F-0.30- 36.84 D-0.15- 18.57 D-

$0.20+2.12 \mathrm{D}-0.25+10.25 \mathrm{D}-0.30+43.05$ D-0.40-

$1.90 \mathrm{HRC}-4+2.36 \mathrm{HRC}-50+0.25 \mathrm{HRC}-52$

+1.46 HRC-54 - 2.18 HRC-56

\subsection{Development of ANN Modelling}

Neural Network model consist of four input neurons and three output corresponding to cutting speed (S), feed-rate (F), work piece hardness (HRC),depth (D) and (FT,FR,FA) respectively by used Hebbian learning rule. The number of the hidden layer and the number of neurons equal to (2) and (4) respectively. Number of input parameters is equal to 4; Figure (6) shows the schematic view of the neural network used.

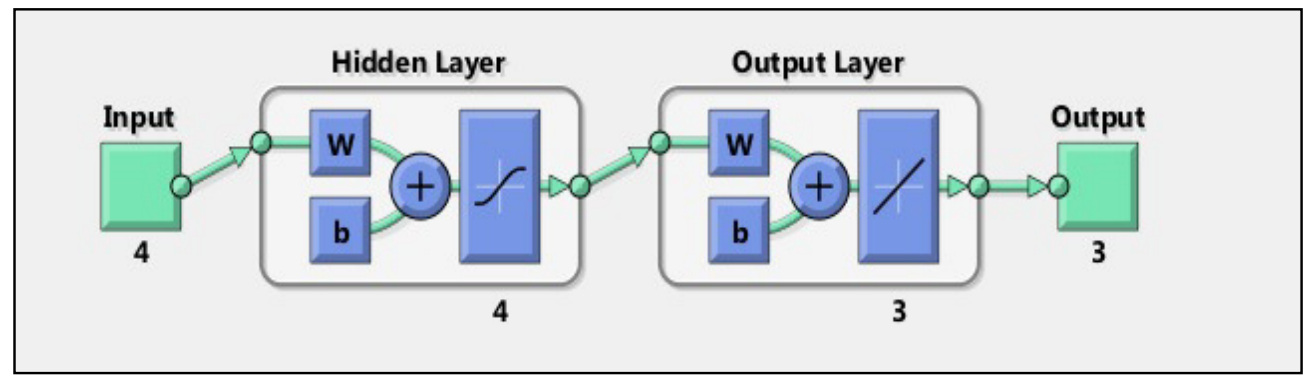

Fig.. 6. the schematic view of the neural network used.

\section{$\underline{\text { Network Model }}$}

Network Kind: Feed Forward Back Propagation Training: Levenberg Maquardtl Algorithm Number Of Layers: 2

Output Layer: 3
Number OF Neurons: 4

Performance: Mean Square Error

Transfer Function For Hidden Layer: Tran Sigmoid Transfer Function for Output: Pure Linear

Adaption of Learning Rate: LEARNGDM 

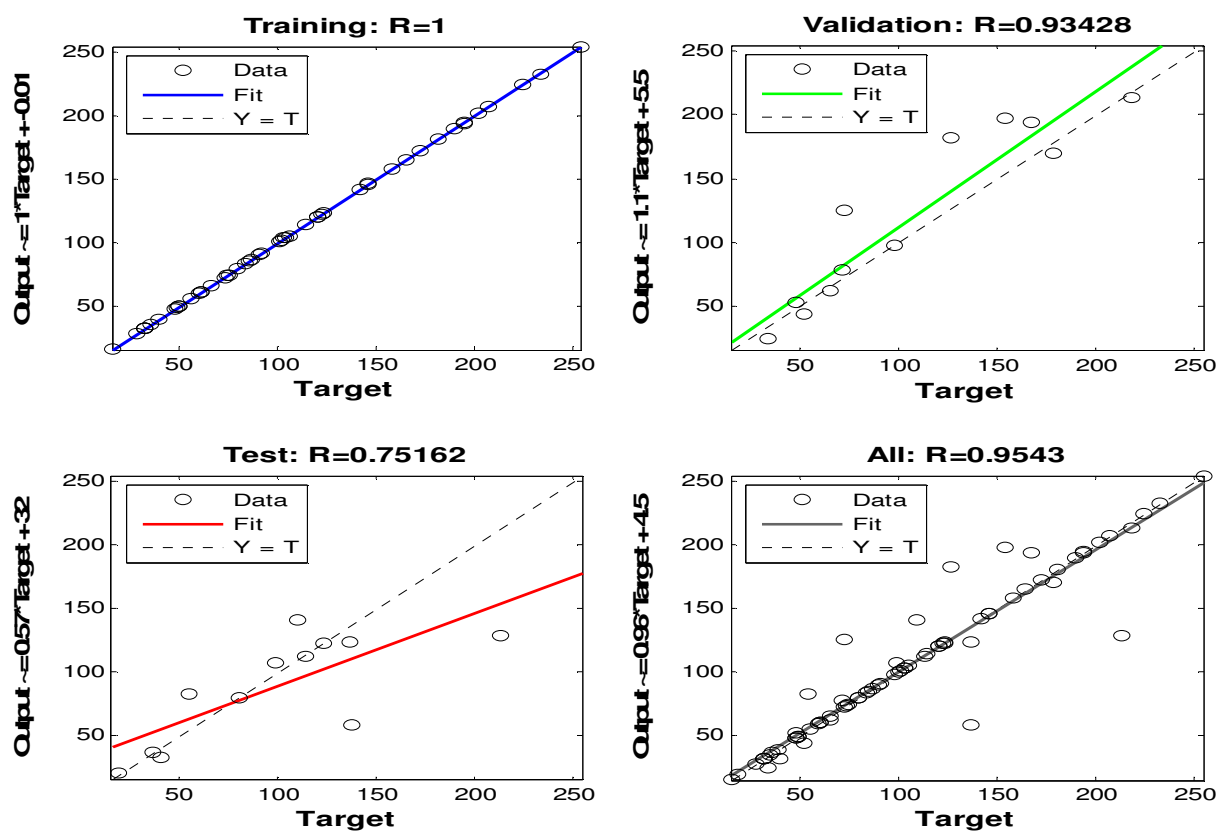

Fig. .7. the graphical representation of the proposed network.

The experimental database is utilized to construct the neural network. About $24 \%$ of data are utilized for model testing, whereas $76 \%$ of data are utilized for model training. Figure (7) show the graphical representation of the proposed network while figure (8) shows the best validation performance was (727.3687) at epoch 6 .

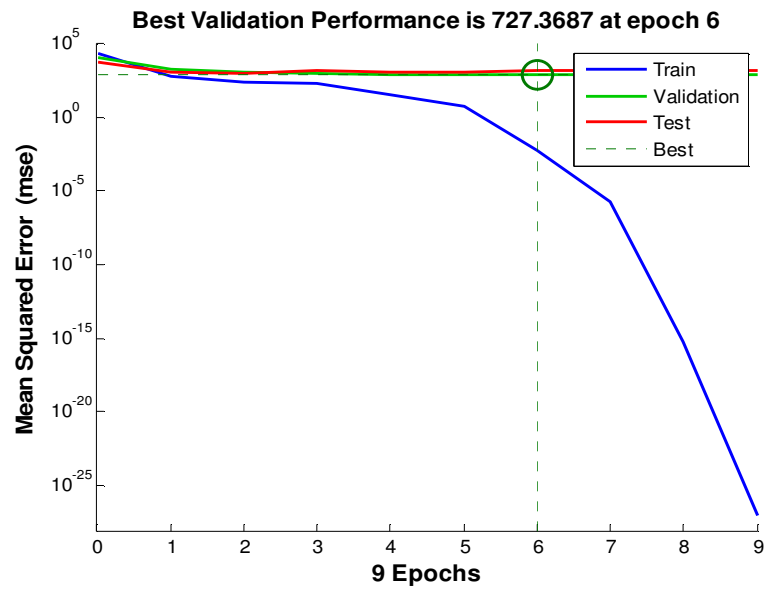

Fig. 8. Mean Square Error-Number of Epochs

Error $\%=$ (Measured- Predicted $) /$ Measured $* 100 \%)$

MSE $=\sum$ (Measured- Predicted) ${ }^{\wedge} 2 /$ number of experiments

Table (9) shows the measured and predicted cutting forces obtained in testing, as well as the mean square error (MSE) values. It can be seen from this table that the average prediction $\operatorname{error}(\bar{\phi})$ found $(4.57 \%, 4.925 \%$, and $4.62 \%)$ the accuracy was $(95.43 \%, 95.075 \%$, and $95.38 \%)$ and MSE $(2.345,40.2$, and $85.37 \%)$ relative to FA, FR, FT respectively. 
Table 9.

Results testing dataset

\begin{tabular}{|c|c|c|c|c|c|c|c|c|c|c|c|c|c|}
\hline & & \multicolumn{4}{|c|}{ Input testing data } & \multicolumn{2}{|c|}{$\mathbf{F A}(\mathbf{N})$} & \multicolumn{3}{|c|}{$\mathbf{F R}(\mathbf{N})$} & \multicolumn{3}{|r|}{$\mathrm{FT}(\mathrm{N})$} \\
\hline $\begin{array}{l}\text { exp } \\
\text { No }\end{array}$ & $\begin{array}{l}\text { depth } \\
\text { of cut }\end{array}$ & speed & feed & $\begin{array}{l}\text { HR } \\
\text { C }\end{array}$ & $\begin{array}{l}\text { Measu } \\
\text { red }\end{array}$ & $\begin{array}{l}\text { Predic } \\
\text { ted }\end{array}$ & $\begin{array}{l}\text { Error } \\
(\%)\end{array}$ & $\begin{array}{l}\text { Measu } \\
\text { red }\end{array}$ & $\begin{array}{l}\text { Predic } \\
\text { ted }\end{array}$ & $\begin{array}{l}\text { Error } \\
(\%)\end{array}$ & $\begin{array}{l}\text { Measu } \\
\text { red }\end{array}$ & $\begin{array}{l}\text { Predic } \\
\text { ted }\end{array}$ & $\begin{array}{l}\text { Error } \\
(\%)\end{array}$ \\
\hline 1 & 0.15 & 100 & 0.05 & 45 & 15.4 & 17.5 & $\begin{array}{l}13.6 \\
4\end{array}$ & 100.3 & 105.1 & 4.79 & 55.3 & 54.7 & 1.08 \\
\hline 5 & 0.15 & 300 & 0.30 & 56 & 32.6 & 31.1 & 4.60 & 122.2 & 111.6 & 8.67 & 164.9 & 179.7 & 8.98 \\
\hline 8 & 0.20 & 250 & 0.15 & 56 & 35.3 & 35.1 & 0.57 & 85.5 & 75.9 & 11.22 & 120.4 & 126.9 & 5.40 \\
\hline 12 & 0.25 & 250 & 0.10 & 45 & 40.2 & 42.3 & 5.22 & 109.5 & 113.3 & 3.47 & 113.6 & 117.2 & 3.17 \\
\hline 19 & 0.30 & 150 & 0.20 & 56 & 60.9 & 61.9 & 1.64 & 103.2 & 102.4 & 0.78 & 172.3 & 169.2 & 1.80 \\
\hline \multirow[t]{2}{*}{24} & 0.40 & 200 & 0.20 & 50 & 79.7 & 81.1 & 1.76 & 194.4 & 195.6 & 0.62 & 206.8 & 221.9 & 7.30 \\
\hline & & & & & \multicolumn{3}{|c|}{$\begin{array}{l}\bar{\phi}(\%)=4.57, \\
\mathrm{MSE}=2.345, \text { Accuracy } \\
(\%)=95.43\end{array}$} & \multicolumn{3}{|c|}{$\begin{array}{l}\bar{\phi}(\%)=4.925, \\
\mathrm{MSE}=40.2, \text { Accuracy } \\
(\%)=95.075\end{array}$} & \multicolumn{3}{|c|}{$\begin{array}{l}\bar{\phi}(\%)=4.62, \\
\mathrm{MSE}=85.37, \text { Accuracy } \\
(\%)=95.38\end{array}$} \\
\hline
\end{tabular}

The expected and empirical values of FA, FR and FT as shown in the testing results in Table (9), which was represented in figures $(9,10, \& 11)$ respectively show that the network gave good interaction with the test data .

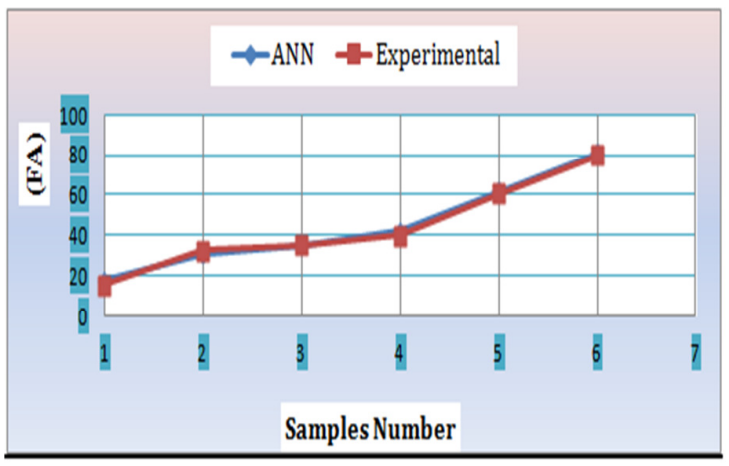

Fig. 9. Experimental \& Predicted FA values for testing data set.

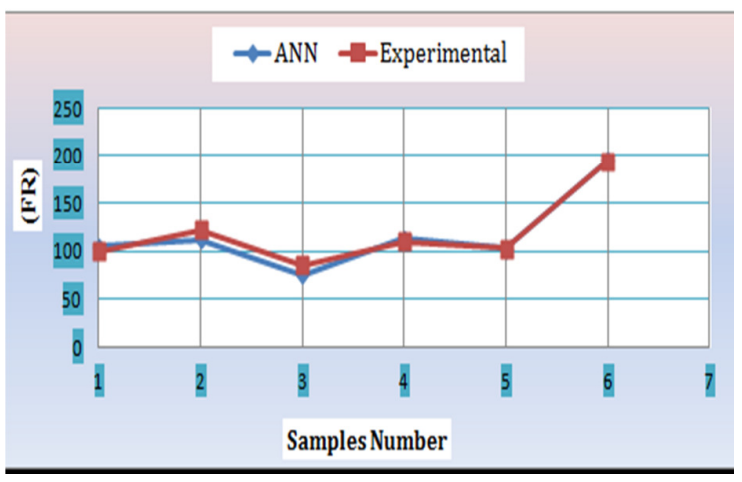

Fig. 10. Experimental \& Predicted FR values for testing data set.

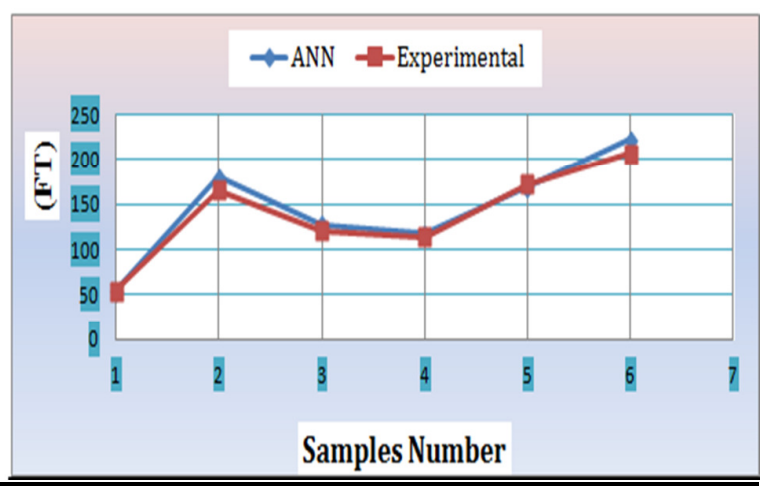

Fig. 11. Experimental \& Predicted FT values for testing data set.

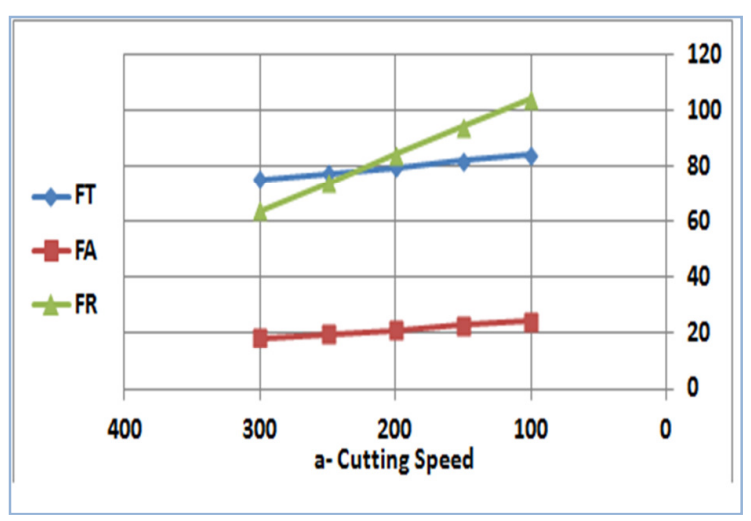



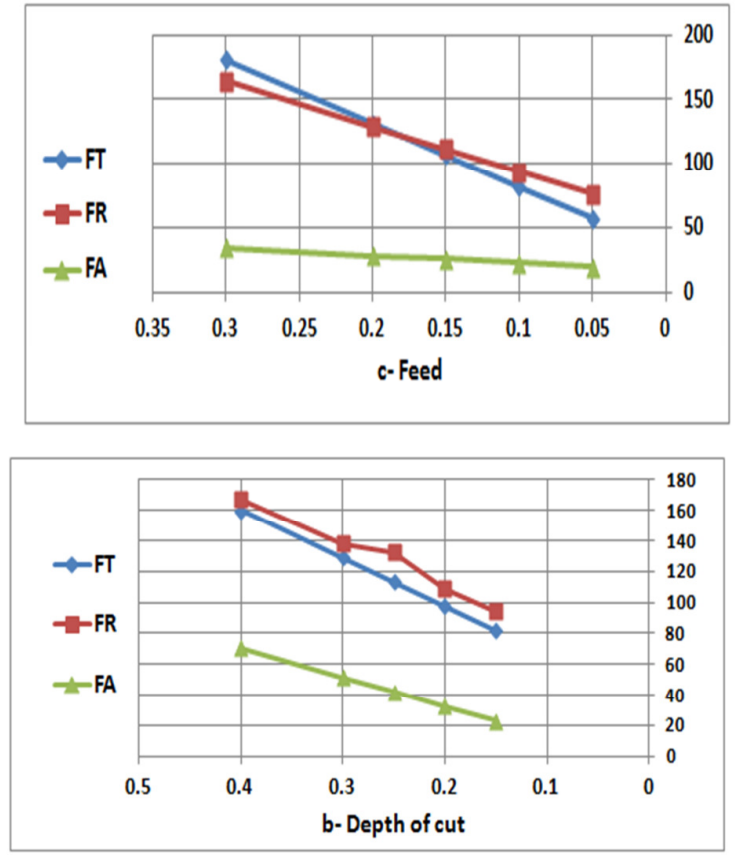

Fig. 12. Experimental testing cutting force components as a function of:

Table 10,

Comparison between ANN vs. Experimental values for cutting forces in training

\begin{tabular}{|c|c|c|c|c|c|c|c|c|c|c|c|c|c|}
\hline No & $\begin{array}{l}\text { Depth } \\
\text { of cut }\end{array}$ & Feed & Speed & HRC & $\begin{array}{l}\text { ANNF } \\
\text { A }\end{array}$ & $\begin{array}{l}\text { Exp } \\
\text { FA } \\
\end{array}$ & $\begin{array}{l}\text { Error( } \\
\%)\end{array}$ & $\begin{array}{l}\text { ANN } \\
\text { FR } \\
\end{array}$ & $\begin{array}{l}\text { Exp } \\
\text { FR } \\
\end{array}$ & $\begin{array}{l}\text { Error( } \\
\%) \\
\end{array}$ & $\begin{array}{l}\text { ANN } \\
\text { FT } \\
\end{array}$ & $\begin{array}{l}\text { Exp } \\
\text { FT } \\
\end{array}$ & Error(\%) \\
\hline 1 & 0.15 & 0.10 & 150 & 50 & 25.2 & 25.9 & 2.70 & 85.5 & 85.5 & 0.00 & 81.5 & 81.2 & 0.36 \\
\hline 2 & 0.15 & 0.15 & 200 & 52 & 28 & 28.2 & 0.70 & 89.7 & 89.7 & 0.00 & 105.3 & 105.3 & 0.00 \\
\hline 3 & 0.15 & 0.20 & 250 & 54 & 29.2 & 29.2 & 0.00 & 95.9 & 95.9 & 0.00 & 129.4 & 129.4 & 0.00 \\
\hline 4 & 0.20 & 0.05 & 150 & 52 & 34.3 & 34.3 & 0.00 & 73.1 & 73.1 & 0.00 & 72.2 & 72.2 & 0.00 \\
\hline 5 & 0.20 & 0.10 & 200 & 54 & 35.3 & 35.3 & 0.00 & 86.3 & 94.2 & 8.38 & 100.3 & 96.3 & 4.15 \\
\hline 6 & 0.20 & 0.20 & 300 & 45 & 36.3 & 36.3 & 0.00 & 123.6 & 123.6 & 0.00 & 136.6 & 136.6 & 0.00 \\
\hline 7 & 0.20 & 0.30 & 100 & 50 & 47.9 & 47.9 & 0.00 & 189.8 & 189.8 & 0.00 & 161.9 & 161.9 & 0.00 \\
\hline 8 & 0.25 & 0.05 & 200 & 56 & 42.7 & 42.5 & 0.81 & 82.3 & 81.8 & 0.61 & 87.3 & 87.2 & 0.11 \\
\hline 9 & 0.25 & 0.15 & 300 & 50 & 39.6 & 39.6 & 0.00 & 114.2 & 114.2 & 0.00 & 145.9 & 145.9 & 0.00 \\
\hline 10 & 0.25 & 0.20 & 100 & 52 & 52.7 & 52.7 & 0.00 & 154.4 & 154.4 & 0.00 & 167.2 & 167.2 & 0.00 \\
\hline 11 & 0.25 & 0.30 & 150 & 54 & 56.1 & 56.1 & 0.00 & 99.6 & 99.6 & 0.00 & 176.9 & 176.9 & 0.00 \\
\hline 12 & 0.30 & 0.05 & 250 & 50 & 48.2 & 48.2 & 0.00 & 80.5 & 80.5 & 0.00 & 96.1 & 96.3 & 0.21 \\
\hline 13 & 0.30 & 0.10 & 300 & 52 & 49.2 & 49.2 & 0.00 & 98.7 & 98.7 & 0.00 & 130.4 & 130.4 & 0.00 \\
\hline 14 & 0.30 & 0.15 & 100 & 54 & 59.8 & 59.9 & 0.16 & 141.9 & 141.9 & 0.00 & 158.1 & 158.2 & 0.06 \\
\hline 15 & 0.30 & 0.30 & 200 & 45 & 63.1 & 63.1 & 0.00 & 190.3 & 190.3 & 0.00 & 184.3 & 184.3 & 0.00 \\
\hline 16 & 0.40 & 0.05 & 300 & 54 & 66.2 & 65.4 & 1.22 & 97.8 & 97.8 & 0.00 & 126.8 & 126.8 & 0.00 \\
\hline 17 & 0.40 & 0.10 & 100 & 56 & 75.9 & 76.1 & 0.26 & 146.1 & 146 & 0.06 & 164.6 & 164.6 & 0.00 \\
\hline 18 & 0.40 & 0.15 & 150 & 45 & 75.1 & 77.9 & 3.68 & 184.1 & 184.1 & 0.00 & 180.9 & 180.9 & 0.00 \\
\hline 19 & 0.40 & 0.30 & 250 & 52 & 82.7 & 82.3 & 0.48 & 198.6 & 198.6 & 0.00 & 189.4 & 189.4 & 0.00 \\
\hline
\end{tabular}

From table (10) the average prediction $\operatorname{error}(\bar{\phi})$ values are found for FA, FR and FT predictions. It was $0.526 \%, 0.476 \%$, and $0.257 \%$, respectively

Figure (13) shows the final graphical comparison between experimental and predicted cutting forces in training. as shown in Table 10, a good and comprehensive match was found a- Cutting speed $(\mathrm{F}=0.1 ; \mathrm{D}=0.15 ; \mathrm{HRC}=45)$

b- Depth of cut $(\mathrm{F}=0.1 ; \mathrm{S}=150 ; \mathrm{HRC}=45)$

c- Feed $(S=150 ; D=0.15 ; \mathrm{HRC}=45)$

As mentioned previously, there are many parameters of the process that have a significant impact on the experimental cutting forces, figure (12) shows the difference of cutting forces with the cutting speed, feed and depth of cut, which can be observed through Figure (12 a, b , c), so it is natural to prefer numerical techniques such as Artificial Neural Networks or Multiple Regression or Genetic algorithm to describe the efficiency of a complex process. 
enhanced by improving some ANN parameters, such as learning rate and momentum

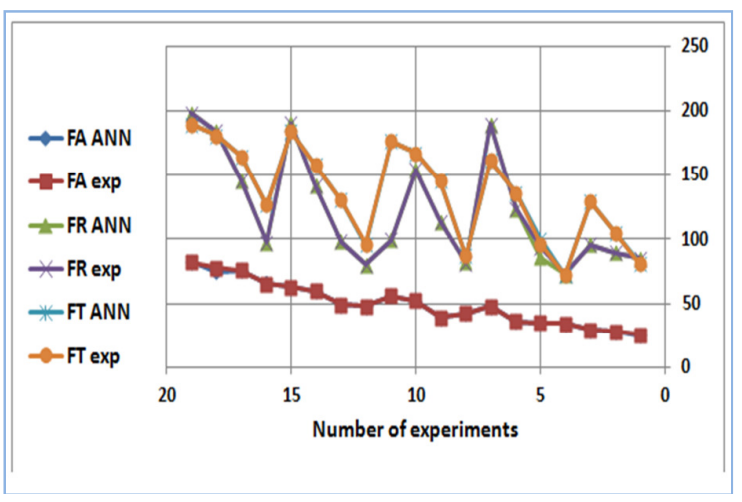

Fig. 13. Comparison between experimental vs. ANN for training

\section{Conclusions}

A model for predicting values of FA, FR and FT were developed by Artificial neural Networks techniques, full factorial design used to implement the empirical design.(ANN) program in MATLAB used to find the relation between the input process parameters and the output variables.

From the ANOVA analysis, found that the most influencing factor on the FR values was the feed with F-ratio (18.88), followed by the depth of the cut with F-ratio (12.88) while the most influence variable on FA was depth of cut with Fratio (333.46) and for FT was feed with F-ratio (861.72).

The better model were chosen dependent on the best performance error for different network components then plotted the graphs between the measured and predicted values in the ANN results, models have been estimated by means of the Percentage deviation between the predict values and the actual values. From training results the average prediction error $(\bar{\phi})$ found $(0.526 \%$, $0.476 \%$, and $0.257 \%$ ) the accuracy was $(99.474 \%$, $99.524 \%, 99.743 \%)$ and $\operatorname{MSE}(0.487 \%, 3.298 \%$, $0.850 \%$ ) relative to FA, FR, FT respectively.

It is clear that the ANN predicted results shows perfect correspond with the empirical results, ANN demonstrate its qualification in optimizing the Turning process parameters. The sophisticated ANN model can be further joined with optimization algorithms like GA to improve the End milling parameters.

\section{References}

[1]Dimla, D. E., Application of perceptron neural networks to tool state classification in metalturning operation. Elsevier, Engineering Applications of Artificial Intelligence, 12, 471-477, 1999.

[2]W. Stachurski, S. Midera and B. Kruszy, "Determination of mathematical formulae for the cutting force FC during the turning of C45 steel," Mechanics and Mechanical Engineering, vol. 16, no. 2, pp. 73-79, 2012.

[3] V. P. Astakhov and X. Xiao, "A Methodology for Practical Cutting Force Evaluation Based on the Energy Spent in the Cutting System," Machining Science and Technology, vol. 12, no. 3, pp. 325-347, 2008.

[4] Gowd G.H., Reddy M.G. and Sreenivasulu B. Empirical modelling of hard turning process of Inconel using response surface methodology. International Journal of Emerging Technology and Advanced Engineering, 2012; ISSN 22502459.

[5]Bouacha, K., Yallese, M . A ., M abrouki, T. and Rigal, J.F. Statistical analysis of surface roughness and cutting forces using response surface methodology in hard turning of AISI 52100 bearing steel with CBN tool, International Journal of Refractory Metals \& Hard Materials, Vol. 28, pp. 349-361. (2010),

[6] Murata, N.; Yoshizawa, S.; Amari, S. Network information criterion-determining the number of hidden units for an artificial neural network model. IEEE Trans. Neural Netw. 5, 8658721994, [CrossRef] [PubMed]

[7] Jain, S.P.; Ravindra, H.V.; Ugrasen, G.; Prakash, G.V.N.; Rammohan, Y.S. Study of surface roughness and $\mathrm{AE}$ signals while machining titanium grade-2 material using ANN in WEDM. In Materials Today: Proceedings; Elsevier: Amsterdam, The Netherlands, pp. 9557-9560, 2017;

[8]Budak, E., Ozlu, E., Development of a thermomechanical cutting process model for machining process simulations, CIRP AnnalsManufacturing Technology, 57, 97-100, 2008.

[9]Szecsi, T., Cutting force modeling using artificial neural networks, Elsevier, Journal of Materials Processing Technology, 92-93, 344349, 1999.

[10] Klancnik, S., Balic, J., Cus, F.: Intelligent prediction of milling strategy using neural networks. Control Cybern, vol. 39, 1, (2010), 9-22. 
[11] Cukor, G., Jurkovic, Z.: Optimization of turning using evolutionary algorithms. Technical Gazette, vol. 30, 2 (2010), 1-10.

[12] Mohanned H. AL-Khafaji ; Neural Network Modeling of Cutting Force and Chip Thickness Ratio For Turning Aluminum Alloy 7075-T6 H. Al-Khwarizmi Engineering Journal, Vol. 14, No. 1, P.P. 6776 (2018)

[13] http://images.app.goo.gl/LnFhrmXH3ZrJXy8 $\underline{\mathrm{c} 8}$
[14] Malinov S, Sha W, Modeling the correlation between processing parameters and properties in titanium alloys using artificaial neural networks, Comput. Mater. Sci. 21 (2001) Page 375 - 394. 


\title{
التنبؤ بقوى القطع في عملية الخراطة باستخدام الثبكة العصبية الاصطناعية
}

\author{
مروى قاسم ابراهيم \\ قسم هنسة الإنتاج والدعادن/ الجامعة التكنولوجية التوبية \\ البريد الالكتروني: uotechnology.edu.iq
}

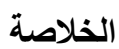

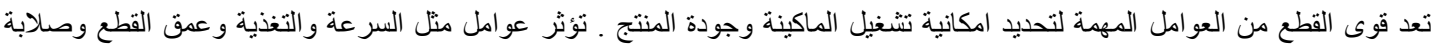

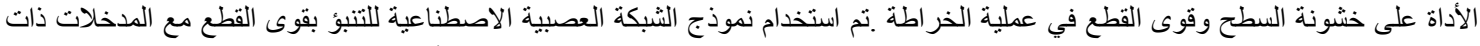

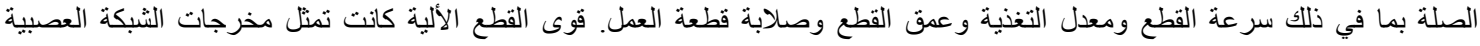

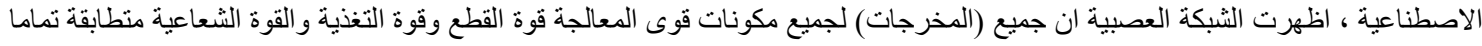

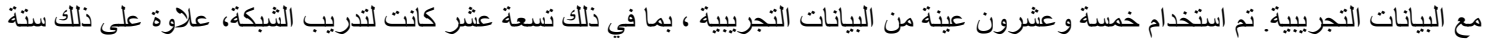

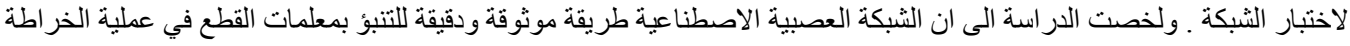

